\title{
The Radio Occultation Processing Package, ROPP
}

\author{
I. D. Culverwell ${ }^{1}$, H. W. Lewis ${ }^{1}$, D. Offiler ${ }^{1}$, C. Marquardt ${ }^{2}$, and C. P. Burrows ${ }^{1}$ \\ ${ }^{1}$ Met Office, Exeter, UK \\ ${ }^{2}$ EUMETSAT, Darmstadt, Germany
}

Correspondence to: I. D. Culverwell (ian.culverwell@metoffice.gov.uk)

Received: 22 October 2014 - Published in Atmos. Meas. Tech. Discuss.: 6 January 2015

Revised: 16 March 2015 - Accepted: 18 March 2015 - Published: 24 April 2015

\begin{abstract}
This paper describes the Radio Occultation Processing Package, ROPP, a product of the EUMETSAT Radio Occultation Meteorology Satellite Application Facility (ROM SAF) developed by a large number of scientists over many years. A brief review of the concepts, functionality and structure of ROPP is followed by more detailed descriptions of its key capabilities. Example results from a full chain of processing using some of the ROPP tools are presented. Some current and prospective uses of ROPP are given. Instructions on how to access the code and its supporting documentation are provided.
\end{abstract}

\section{Introduction}

Radio occultation (RO) observations are an increasingly important means of measuring the tropospheric and stratospheric refractivity, and, indirectly, tropospheric and stratospheric temperature and pressure, and tropospheric humidity (e.g. Kursinski et al., 1997; Anthes, 2011). Their high vertical resolution, freedom from significant bias and global coverage are widely recognised (e.g. Anthes et al., 2008) and have led to the extensive use of RO data for atmospheric research (e.g. Schmidt et al., 2010; Zhang et al., 2010), for assimilation in numerical weather prediction (NWP) models (e.g. Cucurull and Derber, 2008; Healy and Thépaut, 2006; Aparicio and Deblonde, 2008) and for climate monitoring (e.g. Steiner et al., 2011; Ho et al., 2012). It follows that there is a need for widely available, well-supported and fully documented software packages that provide the tools to undertake common $\mathrm{RO}$ data processing requirements. This paper describes one such package, ROPP.
The Radio Occultation Processing Package, ROPP, is provided by EUMETSAT's ${ }^{1}$ Radio Occultation Meteorology Satellite Application Facility (ROM SAF, known as the GRAS SAF before 2012). It comprises software (as source code) and supporting build and test scripts, data files and documentation, which are designed to help users wishing to process, quality-control and assimilate RO data into their NWP models. Facilities are provided for the full chain of RO data processing, from phase delays to bending angles, to refractivities and dry temperatures, and finally to 1D-Var retrieved temperature and humidity profiles.

Although the software is aimed at the GRAS ${ }^{2}$ instrument on the Metop ${ }^{3}$ satellites, as far as is possible it is generic, in that it can handle any other $\mathrm{GNSS}^{4}-\mathrm{LEO}^{5}$ configuration radio occultation mission $\left(\mathrm{COSMIC}^{6}, \mathrm{CHAMP}^{7}\right.$, etc.). We note, however, that a LEO-LEO configuration is not currently supported.

Prospective users can obtain ROPP from the "ROPP Software" link of the ROM SAF home page (http://www.romsaf. org). They can download the entire ROPP distribution, or individual modules. They can integrate a subset of ROPP code into their own software applications, linking individual modules to their own code. Alternatively, they can use the executable tools provided as part of each module as standalone applications for RO data processing. Fully documented build

\footnotetext{
${ }^{1}$ European Organisation for the Exploitation of Meteorological Satellites

${ }^{2}$ GNSS Receiver for Atmospheric Sounding

${ }^{3}$ polar orbiting satellite operated by EUMETSAT

${ }^{4}$ Global Navigation Satellite System

${ }^{5}$ low Earth orbit

${ }^{6}$ Constellation Observing System for Meteorology, Ionosphere, and Climate

${ }^{7}$ Challenging Minisatellite Payload
} 
Table 1. ROPP-7.0 modules and their main functionalities.

\begin{tabular}{ll}
\hline Module & Content \\
\hline UTILS & $\begin{array}{l}\text { Utility tools; units conversion, low-level interfaces, etc. } \\
\text { IO }\end{array}$ \\
$\begin{array}{l}\text { Support for file reading and writing of RO files; RO internal data structure and interfaces; } \\
\text { BUFR encoder/decoder tools; importation of RO data from non-ROPP files; } \\
\text { extraction of background profiles from GRIB2 files; profile thinning; file management }\end{array}$ \\
PP & $\begin{array}{l}\text { Preprocessing (from excess phase through to refractivity and dry temperature); } \\
\text { tropopause height diagnostics }\end{array}$ \\
FM & $\begin{array}{l}\text { Forward models (and tangent linear, adjoints and gradients), 1-D and 2-D versions } \\
\text { 1DVAR }\end{array}$ \\
TEST & $\begin{array}{l}\text { Standalone test harness for ROPP modules. Not a user module, although subsets of the test system are } \\
\text { included with the IO, PP, FM and 1DVAR modules }\end{array}$ \\
\end{tabular}

scripts are provided. A helpdesk is available, and it should be the first point of contact for users in need of advice and information. Support for ROPP is restricted to the current release and the previous two.

This paper describes the status of ROPP-7 (v7.0), which was released in October 2013.

\section{Overview of ROPP}

\subsection{Concept and strategy}

ROPP should not be viewed as a "black box" processor but as a suite of library functions and example applications (written in Fortran 95). The software was originally intended for users who wish to combine RO-specific routines with their own code, but by now ROPP has developed into a package which offers validated standalone tools for format conversion and $\mathrm{RO}$ data processing. Whichever way ROPP is used, users are welcome to modify or replace components in ROPP to suit their existing local systems.

Updates to ROPP - which include new science, modifications in response to new data or software dependencies, and bug fixes - are regularly released by the ROM SAF after a period of review and beta-testing by interested parties.

ROPP functionality mirrors most aspects of the ROM SAF operational data production chain (i.e. the generation of $\mathrm{NRT}^{8}$ refractivity profiles from bending angles) but will not be exactly the same code - although the operational chain will use some elements of ROPP and vice versa. The publicly available version of ROPP also contains additional alternative algorithms as user-switchable options.

\subsection{Main functionality}

ROPP consists of a number of modules, some of which depend on others. Modules not only contain source code but also build and test scripts, data, example test results and user documentation. The ROPP-7.0 modules and their headline

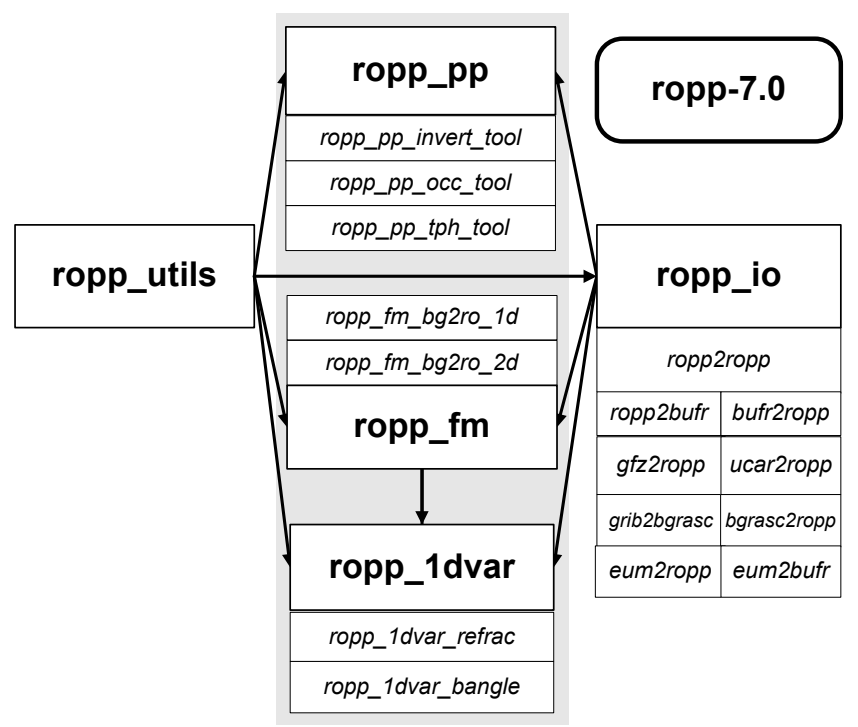

Figure 1. The modules (bold) and tools (italic) within ROPP-7.0. The module at the head of an arrow depends directly on the module at its tail.

functionalities are listed in Table 1, and the relations between them are indicated in Fig. 1. The main purpose and functionality of each module are discussed in the following sections, but, in brief, the two service modules and three scientific modules of ROPP are as follows.

The utilities module of ROPP includes quality control and range-checking tools, and a variety of conversion routines, including co-ordinate transformations (between Earthcentred inertial (ECI) and Earth-centred, Earth-fixed (ECEF) co-ordinates, geopotential and geometric heights, etc.) and date/time and unit conversions.

The input and output module of ROPP provides access to a variety of data formats:

\footnotetext{
${ }^{8}$ near-real time
} 
Table 2. Subroutines in the ROPP UTILS module.

\begin{tabular}{ll}
\hline Name & Purpose \\
\hline GEOMETRIC2GEOPOTENTIAL & Converts geometric heights (w.r.t. ellipsoid) to geopotential heights (w.r.t. geoid) \\
GEOPOTENTIAL2GEOMETRIC & Converts geopotential heights (w.r.t. geoid) to geometric heights (w.r.t. ellipsoid) \\
DATE_AND_TIME_UTC & Calculates current date/time from system clock, adjusted to UTC, from the system time \\
CALTOJUL & Converts Julian Day to calendar date and clock time, and vice versa \\
TIMESINCE & Converts Julian Day (or calendar date and clock time) to the time since some epoch \\
DATUM_HMSL & Converts the height of a point w.r.t. the WGS-84 ellipsoid to the height above the EGM96 geoid \\
DATUM_TRANS & Translates (lon, lat, ht) or $(x, y, z)$ between different Earth system co-ordinates \\
\hline
\end{tabular}

- EUMETSAT's EPS CGS ${ }^{9}$ level 1a NRT products (i.e. excess phase and $\mathrm{POD}^{10}$ in netCDF ${ }^{11}$, and level $1 \mathrm{~b}$ NRT products (i.e. bending angles as a function of impact parameter) in $\mathrm{BUFR}^{12}$;

- ROM SAF level 2 NRT and offline products in netCDF and BUFR;

- UCAR ${ }^{13} / \mathrm{CDAAC}^{14}$ NRT atmPrf, atmPhs, sonPrf, ecmPrf, ncpPrf and gfsPrf products in netCDF, and bfrPrf products in BUFR;

- GFZ ${ }^{15}$ NRT products in dat-dsc text file pairs;

- gridded background field data sets in GRIB2 ${ }^{16}$ format.

ROPP handles these diverse data formats by converting them to its own well-defined RO data structure (in netCDF).

The preprocessing module contains tools to undertake the staged preprocessing from excess phase (i.e. the phase accumulated by the carrier wave during transit of the atmosphere and ionosphere above that which would be accumulated along a straight line path in vacuo between the transmitter and receiver) to bending angle, through to refractivity and dry temperature (Gorbunov et al., 2011). It also contains tools to diagnose tropopause heights from profiles of bending angle, refractivity, dry temperature or background model temperature (Lewis, 2009; WMO, 1957).

The forward modelling module contains forward operators (including tangent linear, adjoint and gradient calculation code) for pressure-based, height-based and hybrid NWP model vertical grids, to generate refractivities and bending angles from model state variables (Healy and Thépaut, 2006). It also includes a 2-D bending angle calculation tool (Healy et al., 2007).

\footnotetext{
${ }^{9}$ European Polar System Core Ground Segment

${ }^{10}$ precise orbit determination data as a function of time

${ }^{11}$ Unidata's Network Common Data Form

${ }^{12}$ Binary Universal Form for data Representation

${ }^{13}$ University Corporation for Atmospheric Research

${ }^{14}$ COSMIC Data Analysis and Archive Center

${ }^{15}$ Helmholtz Centre, Potsdam

${ }^{16}$ General Regularly distributed Information in Binary form, Ed 2
}

The 1D-Var module contains cost function minimisers that allow the retrieval of pressure/height, temperature and humidity profiles from refractivity or bending angle profiles, given colocated NWP model background profiles (Healy and Eyre, 2000; Rennie, 2010).

ROPP also includes sample reference data files and example output test files, as well as full user documentation. Further details of its contents and capabilities can be found in the "ROPP Overview Guide" document at http://www.romsaf. org.

\section{Detailed view of ROPP}

More detailed descriptions of the ROPP modules, and of the third-party software needed to run them, follow.

\subsection{Utility module}

The ROPP UTILS module provides height- and dateconversion routines, and other general purpose library functions such as string handling, message output, array manipulation and basic mathematical routines. These are used by other ROPP modules and would probably not be called directly by users from their own programs. Table 2 lists some of the routines in this module.

ROPP is designed for terrestrial applications. If a user wished to develop RO tools appropriate to other planetary atmospheres, the ROPP UTILS module is where the bulk of the changes (to planetary radius, gravity, rotation rate etc.) would need to be made.

\subsection{Input/output module}

The ROPP IO module reads radio occultation data from a variety of sources (EUMETSAT; BUFR; UCAR; GFZ; and, for background profiles, text and GRIB files) and converts them to ROPP's internal, netCDF-based format for radio occultation data. ROPP can also write out such data in BUFR format. Most of these data-reading tools use data thinning and rangechecking routines which are themselves part of the module. Table 3 lists some of the routines and tools in the IO module.

Figure 2 shows the results of passing a rising COSMIC1 "atmPhs" profile $\left(20.3^{\circ} \mathrm{W}, 19.5^{\circ} \mathrm{S}, 01: 02 \mathrm{UTC}, 1\right.$ Oc- 
Table 3. Subroutines and standalone executables in the ROPP IO module.

\begin{tabular}{|c|c|c|}
\hline & Name & Purpose \\
\hline \multirow{5}{*}{ 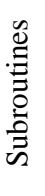 } & ROPP_IO_READ & Reads ROPP-formatted RO data \\
\hline & ROPP_IO_WRITE & Writes ROPP-formatted RO data \\
\hline & ROPP_IO_INIT & Initialises data input and output \\
\hline & ROPP_IO_THIN & Thins profiles \\
\hline & ROPP_IO_RANGECHECK & Range-checks and validates all ROPP parameters \\
\hline \multirow{9}{*}{ 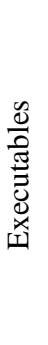 } & ropp2ropp & Copies/renames/reformats/range-checks/thins/orders/splits/concatenates ROPP files \\
\hline & ropp2bufr & Converts ROPP-formatted data file to BUFR format \\
\hline & bufr2ropp & Converts BUFR-formatted data file to ROPP format \\
\hline & ucar2ropp & Converts UCAR-formatted data file to ROPP format \\
\hline & gfz2ropp & Converts GFZ-formatted data file pair to ROPP format \\
\hline & grib2bgrasc & Extracts Fortran namelist of background model data from GRIB2-formatted gridded data set \\
\hline & bgrasc2ropp & Converts Fortran namelist to ROPP format \\
\hline & eum2ropp & Converts netCDF4-formatted ROPP data to standard ROPP format \\
\hline & eum2bufr & Converts netCDF4-formatted ROPP data to BUFR format \\
\hline
\end{tabular}

tober 2012) - containing excess phase and amplitude data, and downloaded from the CDAAC website (http:// cdaac-www.cosmic.ucar.edu/cdaac) - through ucar2 ropp. It also shows the background temperatures and humidities that result when GRIB2-formatted ECMWF analyses, downloaded from the ECMWF website (http://www.ecmwf.int), are passed through grib2bgrasc and bgrasc2ropp.

\subsection{Preprocessing module}

The ROPP PP module has been largely adopted from the OCC code developed by Michael Gorbunov at the Institute for Atmospheric Physics, Moscow. OCC has been shown to generate refractivities that are in excellent agreement (less than $0.2 \%$ systematic difference) with those calculated at UCAR and by forward modelling ECMWF analyses (http: //www.ecmwf.int; Gorbunov et al., 2011).

ROPP PP provides routines to compute L1 and L2 bending angles from excess phase data by geometrical optics and wave optics methods. Ionospherically corrected bending angle profiles are derived by combining L1 and L2 bending angles linearly or in a statistically optimised way. Climatological bending angle profiles are appended above the corrected ones, in order that refractivity profiles can be calculated by means of an inverse Abel transform. Dry temperatures are generated from the refractivities. ROPP PP also contains code to calculate tropopause heights from a variety of fields in an RO profile. Table 4 lists some of the routines and tools in this module.

In more detail, the tools in the ropp_pp module perform the following tasks.

ropp_pp_occ_tool processes excess phase and amplitude data into refractivity, bending angle and dry temperature profiles, in the following steps.

- Read "level 1a" data, i.e. satellite positions, L1 and L2 signal amplitudes and phases.
- Compute the occultation point and undulation (height of geoid minus height of ellipsoid).

- Filter, quality-control and carry out mission-specific processing of amplitude and phase data (Gorbunov et al., 2006).

- Compute bending angles by geometric optics or wave optics (CT2) (Gorbunov and Lauritsen, 2004). By default, ROPP uses CT2 below $25 \mathrm{~km}$ and geometric optics above. The concatenated bending angles are then interpolated onto a common (i.e. the same for L1 and L2) uniformly spaced grid of impact parameters, whose default spacing is $100 \mathrm{~m}$.

- Perform "linearly combined" (LC) ionospheric correction (Vorob'ev and Krasil'nikova, 1994) and "statistically optimised" (OPT) ionospheric correction (Gorbunov, 2002). The latter requires a background bending angle profile, which is currently derived from the MSIS climatology (Hedin, 1991).

- Compute inverse Abel transform of the ionospherically corrected bending angle profile to generate a refractivity profile.

- Generate a dry temperature profile corresponding to this refractivity profile.

- Write results to the RO data structure and thence to the output file.

Figure 3 shows the output of ropp_pp_occ_tool when the unprocessed COSMIC excess phase data shown in Fig. 2 are passed through it. The derived bending angles are also displayed.

ropp_pp_invert_tool is almost the same as ropp_pp_occ_tool, but starts from "level 1b" L1 and 
Table 4. Subroutines and standalone executables in the ROPP PP module.

\begin{tabular}{|c|c|c|}
\hline & Name & Purpose \\
\hline 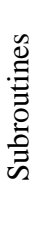 & $\begin{array}{l}\text { ROPP_PP_IONOSPHERIC_CORRECTION } \\
\text { ROPP_PP_INVERT_REFRACTION } \\
\text { ROPP_PP_ABEL } \\
\text { ROPP_PP_BENDING_ANGLE_GO } \\
\text { ROPP_PP_BENDING_ANGLE_WO } \\
\text { ROPP_PP_TDRY }\end{array}$ & $\begin{array}{l}\text { Make ionospheric corrections to L1 and L2 signal } \\
\text { Calculate refractivity profile (inverse Abel transform) } \\
\text { Calculate bending angle profile (Abel transform method) } \\
\text { Calculate bending angle profile (geometrical optics method) } \\
\text { Calculate bending angle profile (wave optics method) } \\
\text { Calculate dry temperature }\end{array}$ \\
\hline 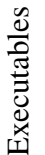 & $\begin{array}{l}\text { ropp_pp_occ_tool } \\
\text { ropp_pp_invert_tool } \\
\text { ropp_pp_tph_tool }\end{array}$ & $\begin{array}{l}\text { Process excess phase data to bending angle to refractivity and dry temperature } \\
\text { Process bending angle data to refractivity and dry temperature } \\
\text { Calculate tropopause height from a bending angle, refractivity, } \\
\text { dry temperature or background temperature profile }\end{array}$ \\
\hline
\end{tabular}

L2 bending angles before generating linearly combined bending angles, statistically optimised bending angles, refractivities and dry temperature profiles, as before.

ropp_pp_tph_tool diagnoses tropopause heights, as follows.

- Read the bending angle, refractivity, dry temperature or background model temperature profile.

- Compute the covariance transform (COT) (Lewis, 2009) of the bending angle or refractivity, or the lapse rate (LRT) of dry temperature or temperature.

- Diagnose the tropopause height (TPH) in the appropriate vertical co-ordinate from the maximum of the COT or the value of the LRT. Also, within the tropics, diagnose the "cold point" tropopause height (CPT) for the temperature-based diagnostics.

- Diagnose and record a TPH quality control (QC) flag, based on confidence in the derived TPH.

- Write the TPH and its QC flag to the RO data structure and thence to the output file.

Figure 4 shows the tropopause heights for the COSMIC occultation and colocated/simultaneous ECMWF background profile used in this paper. All six are reasonably close, and the four "observationally" based TPHs are within $400 \mathrm{~m}$ after the impact altitude of the bending-angle-based TPH has been converted to altitude by dividing by the refractive index at the tropopause (a downward shift of around $200 \mathrm{~m}$ ).

\subsection{Forward modelling module}

The ROPP FM module contains forward operators which calculate refractivity and bending angle profiles from background model data on pressure-based, height-based and "hybrid" NWP model vertical grids. Tangent linear, adjoint and gradient codes of the forward operators are provided for use in assimilation processing. Table 5 lists some of the routines and tools in this module.
In more detail, the tools in the ropp_fm module perform the following tasks.

ropp_fm_bg2ro_1d forward models 1-D background fields into profiles of refractivity and bending angle, in the following steps.

- Read level 2b input model data (ECMWF pressurebased or Met Office height-based) and generate a "state vector" $\boldsymbol{x}$ of pressure $p$, temperature $T$ and humidity $q$ as functions of geopotential height $Z$.

- Read or define (if not in input file) the observation levels on which the output will be calculated.

- Compute the refractivity profile, $N(Z)$ (Kursinski et al., 1997).

- Calculate the bending angle profile, $\alpha(a)$, from the Abel transform of refractivity (Healy and Thépaut, 2006), restricted to non-super-refracting conditions.

- If desired, calculate the forward model gradients $\partial N_{i} / \partial x_{j}$ and $\partial \alpha_{i} / \partial x_{j}$.

The "innovation" curves (i.e. observation minus forward modelled background) in the top two panels of Fig. 5 show the bending angles and refractivities that result from passing the background profiles in the bottom two panels of Fig. 2 through ropp_fm_bg2ro_1d.

ropp_fm_bg2ro_2d extends the forward modelling of ropp_fm_bg 2 ro_ $1 \mathrm{~d}$ by accounting for variation of the refractivity across the occultation plane, rather than just in the vertical at the tangent point. This has been found to have a beneficial effect on $\mathrm{O}-\mathrm{B}$ differences in the lower troposphere (Healy et al., 2007). It works as follows.

- Read 2-D level 2b input model data (ECMWF pressurebased or Met Office height-based) and generate a 2-D state vector $\boldsymbol{x}$ of pressure $p$, temperature $T$ and humidity $q$ as functions of geopotential height $Z$ and (uniformly spaced) horizontal angle $\theta$. 
Table 5. Subroutines and standalone executables in the ROPP FM module.

\begin{tabular}{|c|c|c|}
\hline & Name & Purpose \\
\hline 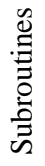 & $\begin{array}{l}\text { ROPP_FM_REFRAC_1D } \\
\text { ROPP_FM_BANGLE_1D } \\
\text { ROPP_FM_BANGLE_2D }\end{array}$ & $\begin{array}{l}\text { Forward model state vector to refractivity } \\
\text { Forward model 1-D state vector to bending angle } \\
\text { Forward model 2-D state vector to bending angle }\end{array}$ \\
\hline 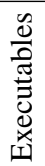 & $\begin{array}{l}\text { ropp_fm_bg2ro_1d } \\
\text { ropp_fm_bg2ro_2d }\end{array}$ & $\begin{array}{l}\text { Standalone tool to map 1-D model profile into bending angle and refractivity profile } \\
\text { Standalone tool to map 2-D model section into bending angle profile }\end{array}$ \\
\hline
\end{tabular}
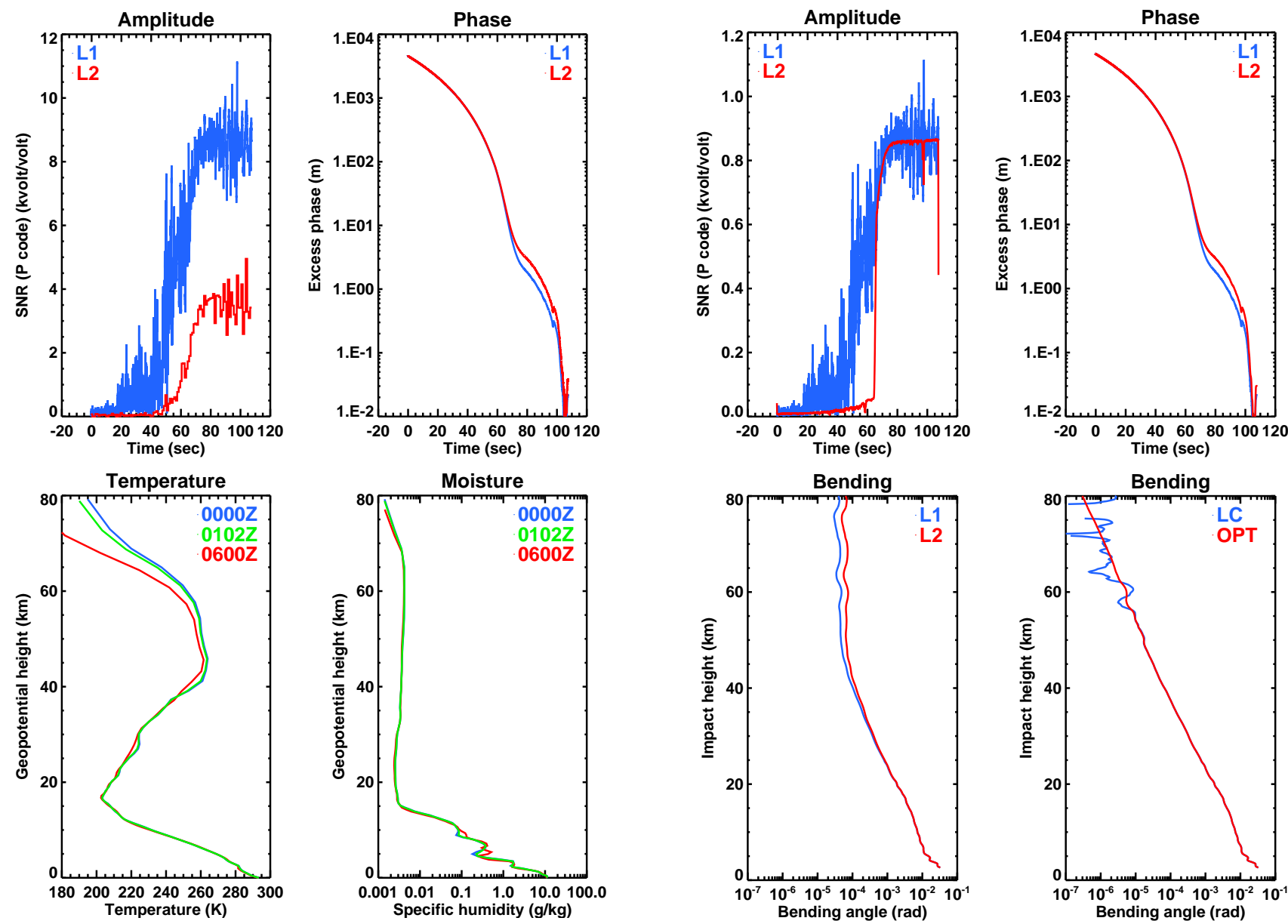

Figure 2. The results of passing "atmPhs" COSMIC data through some of the tools in the ropp_io module. Top left: L1 and L2 signal-to-noise ratios (unprocessed); top right: L1 and L2 excess phases (unprocessed); bottom left: colocated background temperatures extracted from ECMWF analysis/forecast at 00:00 and 06:00 UTC, and the resulting simultaneous profile, obtained by linearly interpolating in time between them, as produced by grib2bgrasc and bgrasc2ropp; bottom right: as bottom left but for specific humidity.

Figure 3. The results of passing the "atmPhs" COSMIC phase/amplitude data of Fig. 2 through ropp_pp_occ_tool. Top left: L1 and L2 signal-to-noise ratios (preprocessed); top right: L1 and L2 excess phases (preprocessed); bottom left: resulting L1 and L2 bending angles; bottom right: "linearly combined" (LC) and "statistically optimised" (OPT) ionospherically corrected bending angles. 

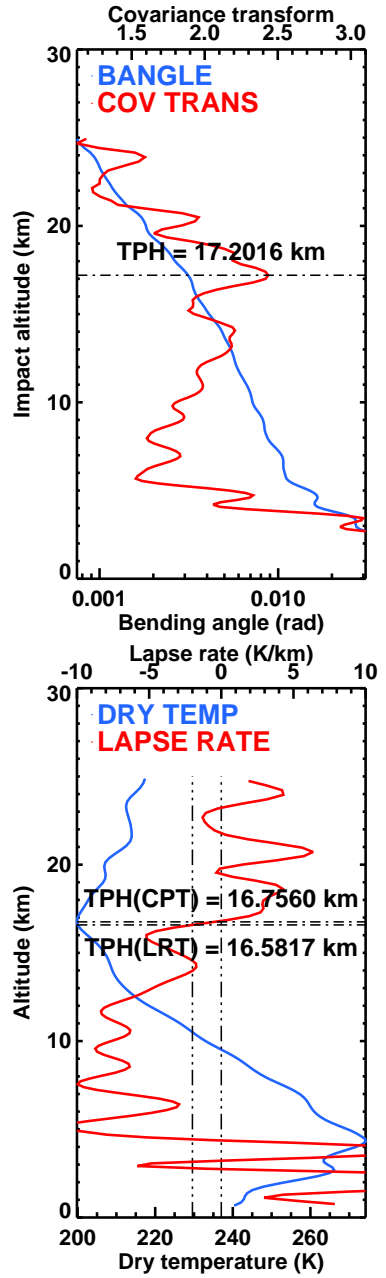
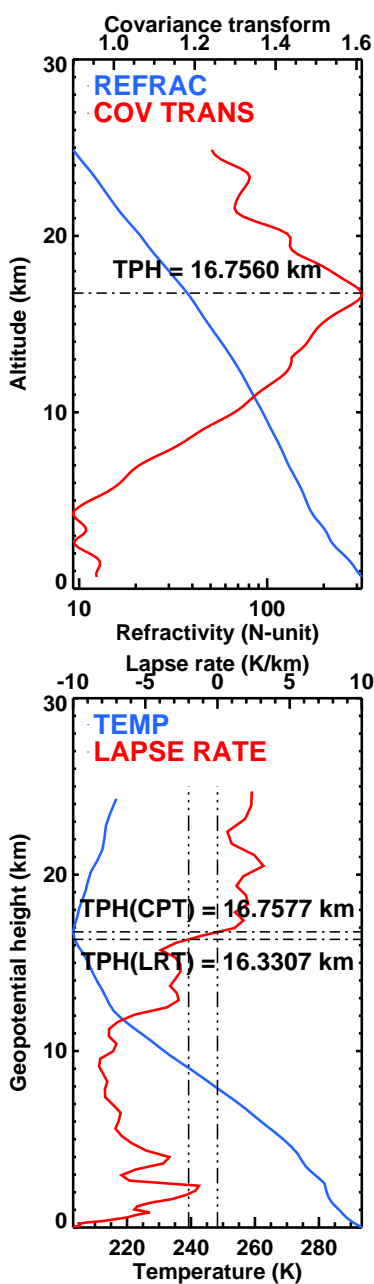
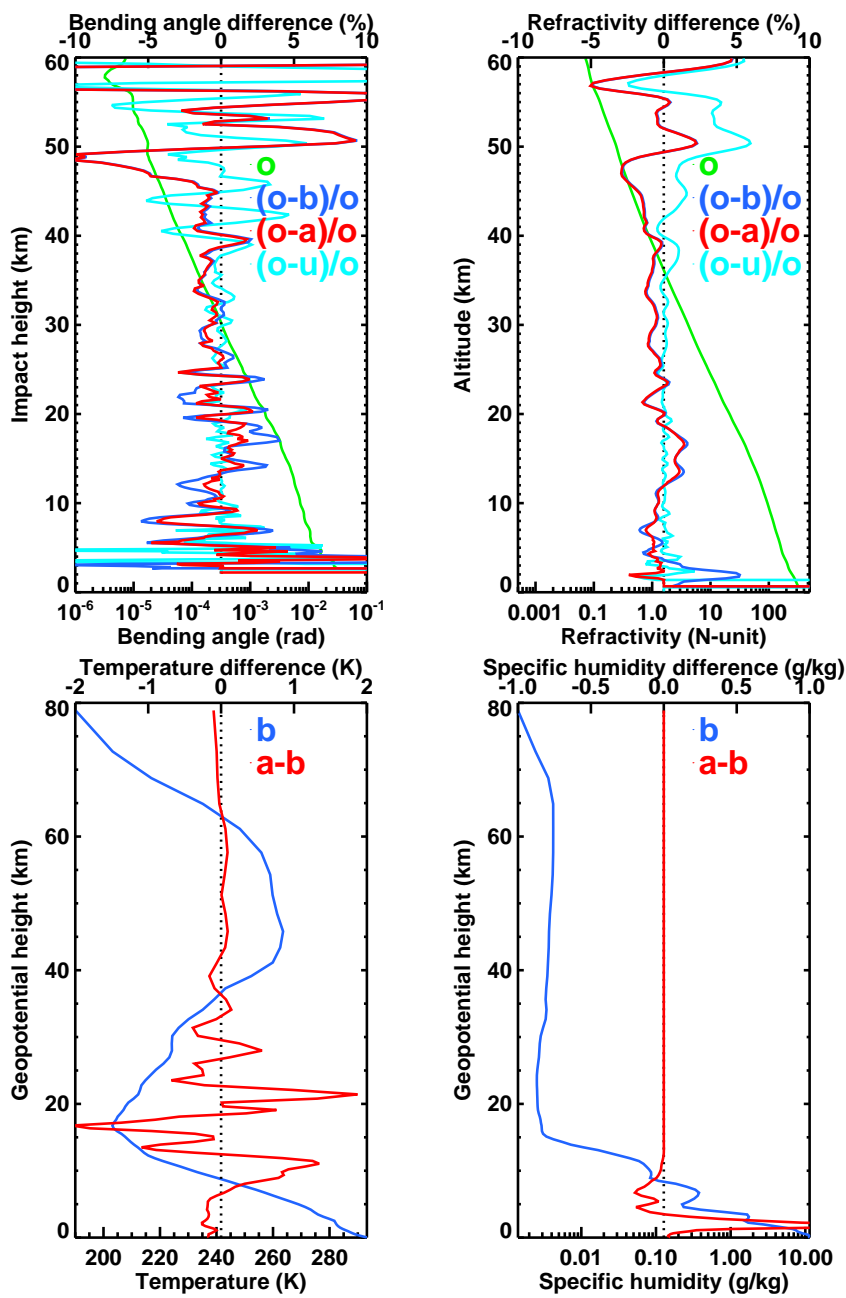

Figure 5. The results of passing COSMIC bending angles and refractivities, and the colocated/simultaneous ECMWF background fields, through ropp_1dvar_bangle and ropp_1dvar_refrac. Top left: observed bending angle profile $\boldsymbol{o}$, as generated by ropp_pp_occ_tool (see Fig. 3), and its fractional difference from the background $\boldsymbol{b}$ and 1D-Var solution $\boldsymbol{a}$, after forward modelling (effectively) by ropp_fm_bg 2 ro_1d. Also included: fractional difference to UCAR-generated bending angle $\boldsymbol{u}$. Top right: same but for refractivity. Bottom left: background temperatures, as generated by grib2bgrasc and bgrasc2ropp (see Fig. 3), and the difference from the solution temperatures, as returned by ropp_1dvar_bangle. Bottom right: as bottom left but for specific humidities.

\subsection{D-Var retrieval module}

The ROPP 1DVAR module provides quality control, minimisation and diagnostic routines for the retrieval of pressure, geopotential height, temperature and humidity profiles from profiles of refractivity or bending angle and (colocated, simultaneous) NWP background profiles, together with error covariance matrices of the observation and background. Table 6 lists some of the routines and tools in this module. 
Table 6. Subroutines and standalone executables in the ROPP 1DVAR module.

\begin{tabular}{|c|c|c|}
\hline & Name & Purpose \\
\hline 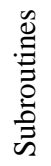 & $\begin{array}{l}\text { ROPP_1DVAR_SOLVE } \\
\text { ROPP_1DVAR_LEVMARQ }\end{array}$ & $\begin{array}{l}\text { Quasi-Newton cost function minimiser } \\
\text { Levenberg-Marquardt cost function minimiser }\end{array}$ \\
\hline 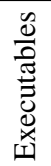 & $\begin{array}{l}\text { ropp_1dvar_refrac } \\
\text { ropp_1dvar_bangle }\end{array}$ & $\begin{array}{l}\text { Standalone 1D-Var retrieval application using refractivity observations } \\
\text { Standalone 1D-Var retrieval application using bending angle observations }\end{array}$ \\
\hline
\end{tabular}

In more detail, the tools in the ropp_1dvar module perform the following tasks.

ropp_1dvar_bangle carries out a 1D-Var minimisation of the usual cost function $J$, where

$2 J(\boldsymbol{x})=(\boldsymbol{x}-\boldsymbol{b})^{T} \mathbf{B}^{-1}(\boldsymbol{x}-\boldsymbol{b})+(\boldsymbol{o}-\mathcal{H}(\boldsymbol{x}))^{T} \mathbf{O}^{-1}(\boldsymbol{o}-\mathcal{H}(\boldsymbol{x}))$,

where $\boldsymbol{x}$ is the state vector, $\boldsymbol{b}$ is the background state vector, $\boldsymbol{o}$ is the vector of bending angle observations, $\mathcal{H}$ is the (non-linear) forward model (Sect. 3.4), B is the background error covariance matrix and $\mathbf{O}$ is the covariance matrix of the combined measurement and forward model error. It works as follows.

- Read input model data (ECMWF pressure-based or Met Office height-based) and generate the background state vector $\boldsymbol{b}$ of temperature $T$ and humidity $q$ as functions of geopotential height $Z$.

- Read the background error matrix B. The correlations usually come from an auxiliary file. The diagonal elements, the variances, can also be supplied externally or profile-by-profile in the background file.

- Read the bending angles on impact parameters to generate the observation vector $\boldsymbol{o}$.

- Read the bending angle error covariance matrix $\mathbf{O}$. The correlations usually come from an auxiliary file. (The bending angle correlation matrix is usually assumed to be the identity.) The diagonal elements, the variances, can also be supplied externally or profile-by-profile in the observation file.

- Carry out quality control based on range-checking, O-B (i.e. $\boldsymbol{o}-\mathcal{H}(\boldsymbol{b}))$ and probability of gross error, and generate diagnostics if desired.

- Minimise the cost function in Eq. (1), either using an ROPP-specific minimiser based on a quasi-Newton method (Nocedal, 1980) or a Levenberg-Marquardt minimiser (Marquardt, 1963). The "solution" $\boldsymbol{a}$ equals $\boldsymbol{x}$ at the minimum $J$.
- Forward model bending angles from solution state vector $\boldsymbol{a}$.

- Generate O-A (i.e. $\boldsymbol{o}-\mathcal{H}(\boldsymbol{a}))$ and analysis error covariance matrix $\mathbf{A}$.

- Write to RO data structure and thence to output file.

Figure 5 shows the result of passing the (LC) bending angle profile shown in Fig. 3 and the colocated ECMWF background profile shown in Fig. 2 through ropp_1dvar_bangle. The retrieval has generally pulled the background towards the observations, as expected. Temperature increments of around $1 \mathrm{~K}$ and specific humidity increments of around $1 \mathrm{~g} \mathrm{~kg}^{-1}$ near the surface result.

Figure 5 also compares the ROPP-derived bending angles and refractivities with those in the corresponding "atmPrf" file, as processed by UCAR. Below $40 \mathrm{~km}$ the ROPP refractivities are closer to those of UCAR than they are to the forward modelled ECMWF background, which lends confidence to the integrity of the ROPP refractivities for this occultation. Above $40 \mathrm{~km}$ the ROPP refractivities are up to $5 \%$ larger than those of UCAR. This may be due to different statistical optimisation (blending of noisy bending angles with smoother climatology) applied in the two codes. ROPP is closer to the ECMWF background in this regime.

The UCAR and ROPP bending angles are also closer to each other than either is to the forward modelled ECMWF background between 10 and $40 \mathrm{~km}$. Below $10 \mathrm{~km}$ the difference between UCAR and ROPP is possibly due to different treatments of the open loop data in this regime. Above $40 \mathrm{~km}$ the differences may again be due to different statistical optimisation in the two codes.

ropp_1dvar_refrac does the same as ropp_1dvar_bangle but uses refractivity observations instead of bending angles. Naturally, different observation background errors $\mathbf{O}$ are needed.

The O-B and O-A profiles of a retrieval based on the refractivities generated (automatically) by ropp_pp_occ_tool, by inverse Abel transform of the bending angles of Fig. 3, are shown in the top right element of Fig. 5. Again, the 1D-Var retrieval procedure has 
Table 7. Elements of the ROPP TEST module.

\begin{tabular}{ll}
\hline Name & Purpose \\
\hline CC & Compile and link all modules on a variety of compilers and platforms \\
IO & Convert between various RO data formats; compare against references \\
PP & Test consistency between Abel and inverse Abel transforms; compare ROPP-generated refractivities and bending angles \\
& against NRT profiles; check processing of raw sampling data. Compare calculated TPHs with reference values \\
FM & Forward model ECMWF and Met Office backgrounds; compare to GRAS, CHAMP and COSMIC observations \\
& FASCOD/ducting examples. Test 2-D operator \\
1DVAR & Test refractivity and bending angle retrieval tools by analysing O-A and O-B \\
\hline
\end{tabular}

drawn the background to the observations. (Note that the temperature and humidity increments in this figure come from the bending angle retrieval.)

\subsection{Testing module}

The ROPP TEST module comprises a comprehensive suite of test routines, and associated test data sets, which can be run on a range of compilers and platforms. This "Test Folder" is one of the main ways of formally validating the ROPP code prior to public release of a new major version of the package. Table 7 lists some of the elements of this module.

Note that the complete ropp_test suite is not intended for users but for internal validation of the ROPP code, although some functionality of ropp_test is included in ropp_io, ropp_pp, ropp_fm and ropp_1dvar for users to verify that the code has been correctly built.

\subsection{Third-party software}

Full implementation of ROPP requires the installation of some standard freely available third-party software packages, principal among which is the netCDF library for general data input and output. Some tools need access to a BUFR library for reading or writing NWP data in that format. Another uses routines in a GRIB library to extract background profiles from a gridded data set. The ROPP documentation clearly indicates which packages are needed by which modules and tools. Naturally, any licence restrictions associated with these packages must be adhered to by ROPP users.

\section{Uses of ROPP}

It is important to realise that ROPP is designed to be used both as a research tool and for operational processing.

The following organisations use, or intend shortly to use, ROPP in their operational systems, where its main use is in the assimilation of RO data.

- The ROM SAF uses ROPP algorithms to generate operational refractivity profiles from bending angles provided by EUMETSAT, and code based on ROPP to generate retrieved temperature and humidity profiles from those refractivities (Lauritsen et al., 2011). ROPP is also used in the ROM SAF's offline operational processing of gridded climate products, which starts from excess phase and amplitude data (http://www.romsaf.org).

- EUMETSAT uses ROPP for validation and monitoring of GRAS data. The ROPP FM module is used to forward model ECMWF background data to bending angles, and the ROPP IO module is used to put GRAS and COSMIC data in the same format. EUMETSAT will also use ROPP for the generation of BUFR data in the next operational processor (A. von Engeln, personal communication, 2014).

- The Naval Research Laboratory (NRL, Monterey, USA) implemented the ROPP bending angle forward model in the operational variational assimilation system run by the Fleet Numerical Meteorology and Oceanography Center (FNMOC) (B. Ruston, personal communication, 2014).

- The Japanese Meteorological Agency (JMA) use ROPP operationally to assimilate bending angles (H. Owada, personal communication, 2014).

- The Korea Institute of Atmospheric Prediction Systems (KIAPS) intend to use ROPP to assimilate bending angles into their new data assimilation system (H. Kwon, personal communication, 2014).

- The Centro de Previsão de Tempo e Estudos Climáticos (CPTEC, Brazil) use ROPP's forward modelling and quality control tools for the assimilation of refractivities in their research data assimilation system. They hope to start pre-operational testing soon (L. Sapucci, personal communication, 2014).

- The Chinese Academy of Sciences (CAS) are considering whether to use ROPP in the preprocessing of data from the GNOS instrument (W. Bai, personal communication, 2014).

Forward models based on the implementations in ROPP are also used operationally at the Met Office and ECMWF (S. Healy, personal communication, 2014). 


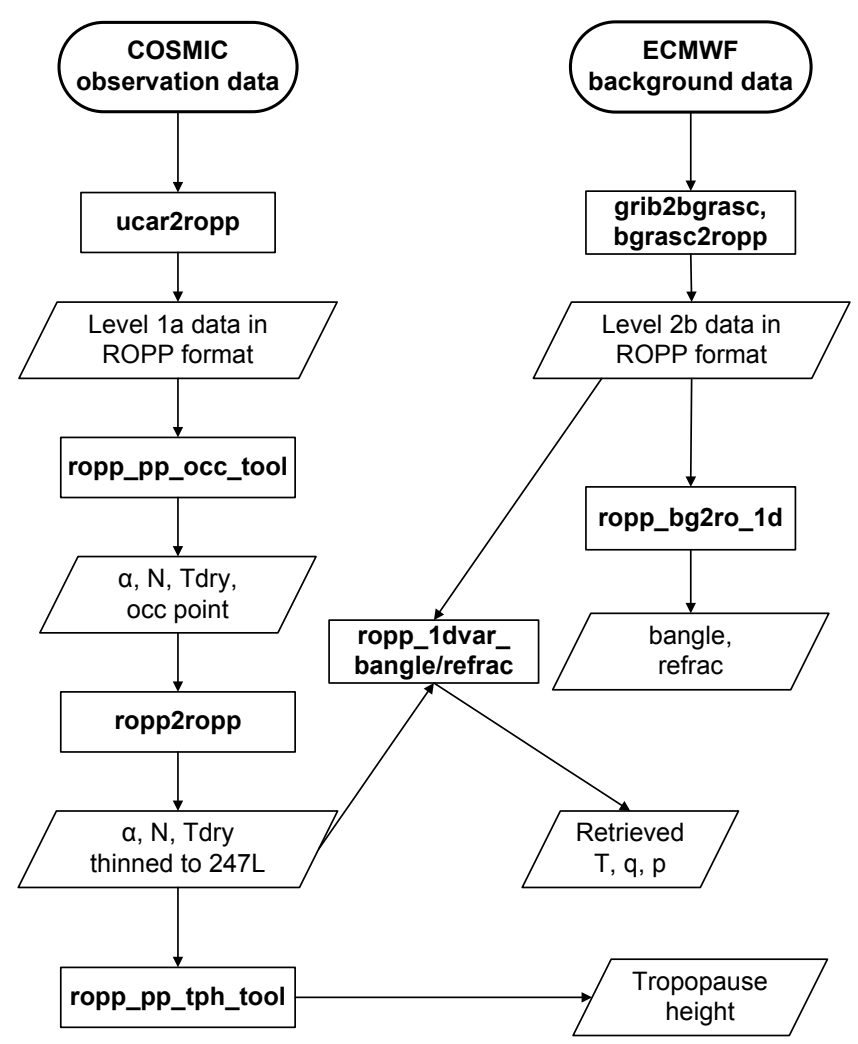

Figure 6. Data flow in the "full chain" of processing described in this paper. Analogous flowcharts would apply if starting from, for example, CHAMP RO data from GFZ and background data from the Met Office NWP model. For brevity, $\alpha$ and "bangle" denote bending angle, while $N$ and "refrac" denote refractivity.

Although ROPP is used extensively within the ROM SAF as a research tool, it is beginning to be used more widely, as in the following examples.

- Zhang et al. (2010) used ROPP to examine the effect of ionospheric correction on radio occultation measurements over Australia.

- Zin et al. (2012) investigated the properties of the ROSA GNSS receiver with ROPP.

- Ringer and Healy (2008) investigated climatological trends in bending angle using the ROPP forward model algorithms.

- Von Engeln et al. 2009 compared bending angle observations made by the GRAS instrument to ECMWF forecasts which were forward modelled with (effectively) ROPP.

As ROPP is developed, new functionality will be introduced, which, it is hoped, will be of interest to researchers in a range of areas.

\section{Conclusions}

This paper has given a brief overview of the Radio Occultation Processing Package. Its structure and functionality have been briefly described, and details of its key software tools have been given. Results have been shown of a "full chain" of ROPP processing, from COSMIC data files and ECMWF background fields to ionospherically corrected bending angles and refractivities, to 1D-Var retrievals of temperature and humidity. Example tropopause height diagnostics of the resulting profiles have also been shown. Figure 6 summarises the full data flow.

Past, present and future examples of the use of ROPP have been given. The hope is that this paper may encourage other radio occultation scientists to try using ROPP to process their data.

Further information on the use of ROPP within the ROM SAF can be found from the "Publications" link of the ROM SAF home page (http://www.romsaf.org). This page also has links to ROM SAF reports, conference proceedings, articles and other publications of interest to those in the field of radio occultation. 


\section{Appendix A}

Table A1. Contributors to ROPP.

\begin{tabular}{|c|c|c|}
\hline Name & Current institute & Contribution \\
\hline Christian Marquardt & EUMETSAT & $\begin{array}{l}\text { Author of majority of ROPP-1 code in UTILS, IO, FM and 1DVAR } \\
\text { modules, and much personal, pre-existing software }\end{array}$ \\
\hline Huw Lewis & Met Office & $\begin{array}{l}\text { 1st ROPP development manager; FM and 1DVAR extensions, } \\
\text { PP module }\end{array}$ \\
\hline Dave Offiler & Met Office & $\begin{array}{l}\text { ROPP project manager; IO application code and IO extensions, } \\
\text { BUFR format/template }\end{array}$ \\
\hline Sean Healy & ECMWF & $\begin{array}{l}\text { Original 1-D FM code, 2-D FM operator code, introduction of } \\
\text { compressibility factors }\end{array}$ \\
\hline Michael Gorbunov & $\begin{array}{l}\text { Russian Academy } \\
\text { of Sciences }\end{array}$ & Original PP code \\
\hline Axel von Engeln & EUMETSAT & $\begin{array}{l}\text { Author of original Test Folder system and of EUMETSAT-formatted } \\
\text { RO data reader }\end{array}$ \\
\hline Stig Syndergaard & DMI & $\begin{array}{l}\text { Original spectral version of MSIS model (expansion in spherical } \\
\text { harmonics and Chebyshev polynomials), PP module developments }\end{array}$ \\
\hline Ian Culverwell & Met Office & $\begin{array}{l}\text { 2nd ROPP development manager; documentation, testing, } \\
\text { consolidation, IO development, GRIB2 reader, } \\
\text { implementation of tropopause height diagnostics }\end{array}$ \\
\hline Carlo Buontempo & Met Office & Savitzky-Golay thinner code \\
\hline Michael Rennie & ECMWF & 1st ROPP test manager; Test Folder developments \\
\hline Kjartan Kinch & DMI & Elements of ropp_pp \\
\hline Hans Gleisner & DMI & Elements of ropp_pp, prototype GRIB2 reader \\
\hline Torsten Schmidt & GFZ & Guidance on tropopause height diagnostics \\
\hline Chris Burrows & Met Office & 2nd ROPP test manager; Test Folder developments \\
\hline Kent Bærkgaard Lauritsen & DMI & $\begin{array}{l}\text { Code reviews; liaison with EUMETSAT } \\
\text { (licences, beta tester contracts) }\end{array}$ \\
\hline
\end{tabular}


Acknowledgements. This work was carried out as part of EUMETSAT's Radio Occultation Meteorology Satellite Application Facility (ROM SAF), which is a decentralised operational RO processing centre under EUMETSAT. I. D. Culverwell, D. Offiler and C. P. Burrows are members of the ROM SAF.

We thank UCAR/CDAAC for providing the COSMIC excess phase data and ECMWF for the gridded background fields that were used in the ROPP data processing example.

Many people, inside and outside the ROM SAF, have contributed to the development of ROPP. The principal authors are listed in Table A1. The ROM SAF extends its sincere appreciation for their efforts.

Edited by: A. K. Steiner

\section{References}

Anthes, R. A.: Exploring Earth's atmosphere with radio occultation: contributions to weather, climate and space weather, Atmos. Meas. Tech., 4, 1077-1103, doi:10.5194/amt-4-1077-2011, 2011.

Anthes, R. A., Bernhardt, P. A., Chen, Y., Cucurull, L., Dymond, K. F., Ector, D., Healy, S. B., Ho, S.-P., Hunt, D. C., Kuo, Y.-H., Liu, H., Manning, K., McCormick, C., Meehan, T. K., Randel, W. J., Rocken, C., Schreiner, W. S., Sokolovskiy, S. V., Syndergaard, S., Thompson, D. C., Trenberth, K. E., Wee, T.-K., Yen, N. L., and Zeng, Z.: The COSMIC/FORMOSAT-3 Mission: Early Results, B. Am. Meteorol. Soc., 89, 313-333, doi:10.1175/BAMS-89-3-313, 2008.

Aparicio, J. M. and Deblonde, G., 2008: Impact of the Assimilation of CHAMP Refractivity Profiles on Environment Canada Global Forecasts. Mon. Weather Rev., 136, 257-275, doi:10.1175/2007MWR1951.1, 2008.

Cucurull, L. and Derber, J. C.: Operational implementation of COSMIC observations into NCEP's Global Data Assimilation System, Weather Forecast., 23, 702-711, doi:10.1175/2008WAF2007070.1, 2008.

Gorbunov, M. E.: Ionospheric correction and statistical optimization of radio occultation data, Radio Sci., 37, 1084, doi:10.1029/2000RS002370, 2002.

Gorbunov, M. E. and Lauritsen, K. B.: Analysis of wave fields by Fourier Integral Operators and their application for radio occultations, Radio Sci., 39, RS4010, doi:10.1029/2003RS002971, 2004.

Gorbunov, M. E., Lauritsen, K. B., Rhodin, A., Tomassini, M., and Kornblueh, L.: Radio holographic filtering, error estimation, and quality control of radio occultation data, J. Geophys. Res., 111, D10105, doi:10.1029/2005JD006427, 2006.

Gorbunov, M. E., Shmakov, A. V., Leroy, S. S., and Lauritsen, K. B.: COSMIC Radio Occultation Processing: Cross-Center Comparison and Validation, J. Atmos. Ocean. Tech., 28, 737-751, doi:10.1175/2011JTECHA1489.1, 2011.

Healy, S. B. and Eyre, J. R.: Retrieving temperature, water vapor and surface pressure information from refractive-index profiles derived by radio occultation: A simulation study, Q. J. Roy. Meteor. Soc., 126, 1661-1683, doi:10.1002/qj.49712656606, 2000.
Healy, S. B. and Thépaut, J.-N.: Assimilation experiments with CHAMP GPS radio occultation measurements, Q. J. Roy. Meteor. Soc., 132, 605-623, doi:10.1256/qj.04.182, 2006.

Healy, S. B., Eyre, J. R., Hamrud, M., and Thépaut, J.-N.: Assimilating GPS radio occultation measurements with two-dimensional bending angle observation operators, Q. J. Roy. Meteor. Soc., 133, 1213-1227, doi:10.1002/qj.63, 2007.

Hedin, A. E.: Extension of the MSIS thermosphere model into the middle and lower atmosphere, J. Geophys. Res., 96, 1159-1172, doi:10.1029/90JA02125, 1991.

Ho, S.-P., Hunt, D., Steiner, A. K., Mannucci, A. J., Kirchengast, G., Gleisner, H., Heise, S., von Engeln, A., Marquardt C., Sokolovskiy, S., Schreiner, W., Scherllin-Pirscher, B., Ao, C., Wickert, J., Syndergaard, S., Lauritsen, K., Leroy, S., Kursinski, E. R., Kuo, Y.-H., Foelsche, U., Schmidt, T., Gorbunov, M., Reproducibility of GPS radio occultation data for climate monitoring: Profile-to-profile inter-comparison of CHAMP climate records 2002 to 2008 from six data centers, J. Geophys. Res., 117, D18111, doi:10.1029/2012JD017665, 2012.

Kursinski, E. R., Hajj, G. A., Schofield, J. T., Linfield, R. P., and Hardy, K. R.: Observing earth's atmosphere with radio occultation measurements using the Global Positioning System, J. Geophys. Res., 102, D19, 23429-23465, doi:10.1029/97JD01569, 1997.

Lauritsen, K. B., Syndergaard, S., Gleisner, H., Gorbunov, M. E., Rubek, F., Sørensen, M. B., and Wilhelmsen, H.: Processing and validation of refractivity from GRAS radio occultation data, Atmos. Meas. Tech., 4, 2065-2071, doi:10.5194/amt-4-2065-2011, 2011.

Lewis, H. W.: A robust method for tropopause altitude identification using GPS radio occultation data, Geophys. Res. Lett., 36, L12808, doi:10.1029/2009GL039231, 2009.

Marquardt, D.: An Algorithm for Least-Squares Estimation of Nonlinear Parameters, SIAM J. Appl. Math., 11, 431-441, 1963.

Nocedal, J.: Updating Quasi-Newton Matrices with Limited Storage, Math. Comput., 35, 773-782, 1980.

Rennie, M. P.: The impact of GPS radio occultation assimilation at the Met Office, Q. J. Roy. Meteor. Soc., 136, 646, A, 116-131, doi:10.1002/qj.521, 2010.

Ringer, M. A. and Healy, S. B.: Monitoring twenty-first century climate using GPS radio occultation bending angles, Geophys. Res. Lett., 35, L05708, doi:10.1029/2007GL032462, 2008.

Rodgers, C. D.: Inverse Methods for Atmospheric Sounding: Theory and Practice, World Scientific Publishing, Singapore, New Jersey, London, Hong Kong, 2000.

Schmidt, T., Wickert, J. and Haser, A.: Variability of the upper troposphere and lower stratosphere observed with GPS radio occultation bending angles and temperatures, Adv. Space Res., 46, 150-161, doi:10.1016/j.asr.2010.01.021, 2010.

Steiner, A. K., Lackner, B. C., Ladstädter, F., Scherllin-Pirscher, B., Foelsche, U., Kirchengast, G., GPS radio occultation for climate monitoring and change detection, Radio Sci., 46, RSOD24, doi:10.1029/2010RS004614, 2011.

von Engeln, A., Healy, S., Marquardt, C., Andres, Y., and Sancho, F.: Validation of operational GRAS radio occultation data, Geophys. Res. Lett., 36, L17809, doi:10.1029/2009GL039968, 2009.

Vorob'ev, V. V. and Krasil'nikova, T. G.: Estimation of the Accuracy of the Atmospheric Refractive Index Recovery from Doppler 
Shift Measurements at Frequencies Used in the NAVSTAR System, Physics of the Atmosphere and Ocean, 29, 602-609, 1994 (English translation).

World Meteorological Organisation: Definition of the tropopause, WMO Bull., 6, 136, 1957.

Zhang, K., Le Marshall, J., Norman, R., Wang, C.-S., Fu, E., Li, Y., and Kuleshov, Y.: A study on the relationship between ionospheric correction and data control for GPS radio occultation in Australia, in: Proceedings of Geoscience and Remote Sensing Symposium (IGARSS), Honolulu, Hawaii, 25-30 July 2010, 2940-2943, doi:10.1109/IGARSS.2010.5650216, 2010.
Zin, A., Zago, S., Mangolini, E., Landenna, S., Marradi, L., Notarpietro, R., Radicella, S., Nava, B., and Catalano, V.: The ROSA radio occultation project, in Proceedings of Satellite Navigation Technologies and European Workshop on GNSS Signals and Signal Processing, (NAVITEC), Nordwijk, the Netherlands, 57 December 2012, 1-8, doi:10.1109/NAVITEC.2012.6423096, 2012. 